\title{
ESE audit on management of adult growth hormone deficiency in clinical practice
}

\section{Luciana Martel-Duguech $(1)$, Jens Otto L Jorgensen ${ }^{2,3}$, Márta Korbonits ${ }^{4,5}$, Gudmundur Johannsson ${ }^{6,7}$ and Susan M Webb 101 on behalf of the ESE AGHD Study Group* for a Pan-European audit}

'IIB-Sant Pau and Department of Endocrinology/Medicine, Hospital Sant Pau, Universitat Autónoma de Barcelona, and Centro de Investigación Biomédica en Red de Enfermedades Raras (CIBER-ER, Unit 747), ISCIII, Barcelona, Catalunya, Spain, ${ }^{2}$ Clinical Lead, Pituitary and Neuroendocrinology, European Society of Endocrinology, Starling House, Bristol, UK, ${ }^{3}$ Department of Clinical Medicine - The Department of Endocrinology and Diabetes, Arhus, Denmark, ${ }^{4}$ Adult Chair of the Endo-ERN Research \& Science Workpackage and member of Endo-ERN Pituitary Thematic Group, ${ }^{5}$ Endocrinology, William Harvey Research Institute, Barts and The London School of Medicine and Dentistry, Queen Mary University of London, Charterhouse Square, London, UK, ${ }^{6}$ Member of Endo-ERN Growth and Genetic Obesity Syndrome Thematic Group, and 7 Institute of Medicine, Sahlgrenska Academy, University of Gothenburg, Göteborg, Sweden

Correspondence should be addressed to S M Webb Email

swebb@santpau.cat or webbsusan4@gmail.com

\section{Abstract}

Guidelines recommend adults with pituitary disease in whom GH therapy is contemplated, to be tested for GH deficiency (AGHD); however, clinical practice is not uniform.

Aims: (1) To record current practice of AGHD management throughout Europe and benchmark it against guidelines; (2) To evaluate educational status of healthcare professionals about AGHD.

Design: Online survey in endocrine centres throughout Europe.

Patients and methods: Endocrinologists voluntarily completed an electronic questionnaire regarding AGHD patients diagnosed or treated in 2017-2018.

Results: Twenty-eight centres from 17 European countries participated, including 2139 AGHD patients, 28\% of childhood-onset GHD. Aetiology was most frequently non-functioning pituitary adenoma (26\%), craniopharyngioma (13\%) and genetic/congenital midline malformations (13\%). Diagnosis of GHD was confirmed by a stimulation test in 52\% (GHRH+arginine: 45\%; insulin-tolerance: $42 \%$, glucagon: 6\%; GHRH alone and clonidine tests: 7\%); in the remaining, $\geq 3$ pituitary deficiencies and low serum IGF-I were diagnostic. Initial GH dose was lower in older patients, but only women $<26$ years were prescribed a higher dose than men; dose titration was based on normal serum IGF-I, tolerance and side-effects. In one country, AGHD treatment was not approved. Full public reimbursement was not available in four countries and only in childhood-onset GHD in another. AGHD awareness was low among non-endocrine professionals and healthcare administrators. Postgraduate AGHD curriculum training deserves being improved.

Conclusion: Despite guideline recommendations, GH replacement in AGHD is still not available or reimbursed in all European countries. Knowledge among professionals and health administrators needs improvement to optimise the care of adults with GHD. Printed in Great Britain 


\section{Introduction}

Adult growth hormone deficiency (AGHD) affects between 200 and 300 patients/million population, approximately 100000 patients across Europe (1). The condition is characterised by a reduction in bone mineral density, lean body mass, exercise capacity, and overall health-related quality of life as well as an increase of body fat and an adverse cardiovascular risk profile $(2,3)$. The concept of AGHD was established more than 30 years ago, and the accumulated evidence is nowadays overwhelming that most patients benefit from a daily injection of GH and are willing to continue treatment $(4,5,6,7,8,9,10,11,12$, $13,14)$. Nevertheless, a small percentage of patients do not perceive any benefit and prefer not to be GH replaced $(15,16)$.

Current guidelines recommend that patients with pituitary disease should be tested and treated for AGHD $(17,18,19,20)$. Still, it is not universally recognised as a distinct entity and reimbursement for GH replacement therapy is not available in some countries. The European Society of Endocrinology (ESE) therefore aimed to investigate the current practice of AGHD management to benchmark it against existent guidelines $(17,18$, $19,20)$. The goal was to collect aggregated patient data from regional centres representing several thousand individuals, with either treated or untreated AGHD.

\section{Patients and methods}

An ESE Steering Group prepared an online survey to collect information on diagnosis and treatment practices country by country (https://www.ese-hormones.org/ aghd) and to compare everyday practice with guideline recommendations.

Invitations to participate were distributed at ECE2018, through the Rare Endocrine Disease European Reference Network (Endo-ERN) and the ESE Council of Affiliated Societies (ECAS). Suitable centres were those from Europe, who currently treated at least 10 AGHD patients per year or who could not treat AGHD due to local conditions and restrictions. We identified 70 centres which were invited to participate repeatedly, via e-mail. Finally, 28 centres from 17 European countries were included.

The survey consisted of 44 questions (Supplementary Table, see section on supplementary materials given at the end of this article) and included sections on demographics, diagnostic criteria, patient selection, GH dosing and follow up, safety and treatment goals. Patients diagnosed and/or treated between 01/01/2017 and 31/12/2018 were included. Additionally, ten questions reflected the practice and perspectives of each centre as reported by the senior endocrinologist in charge, namely sections on national statistics on AGHD, country treatment reimbursement policies and distribution of the drug, available education and training resources and the level of satisfaction related to AGHD in each local setting. Questions were developed on the basis of published guidelines (17).

Individual patient data were captured in a dedicated Access database (Form A). An aggregated data summary form was generated (Form B), which was the basis of the information submitted to the ESE in an online e-survey (Form C and Supplementary Table), which also captured the questions on local practices and current site-specific perspectives.

Since the survey did not include personal medical questions but a summary of patient data and clinical practise per centre, ethics approval was not required in all countries, however, when necessary, participants obtained local approval by their ethics committee.

\section{Statistical analysis}

Descriptive statistics and Student's t-test, Chi-squared or ANOVA tests were used to analyse the data, where appropriate. A level of $P<0.05$ was considered significant. Analyses were performed using SPSS21.0 (SPSS Inc., Chicago, IL).

\section{Results}

In January 2020, 28 Form C-s (online survey) were collected from 28 centres in 17 countries. The largest contributing countries were Italy (five centres) and Spain (four centres). The general characteristics of participating centres and patients are summarised in Fig. 1.

Based on the published prevalence of AGHD in different countries (1), the estimated and captured AGHD patients per country are shown in Table 1; Denmark (32\%) and Slovenia (20\%) were the countries with the highest participation.

In order to evaluate the global experience of each centre in the management of pituitary patients, the total number of pituitary patients, as well as surgical and radiotherapy treatments per year were collected, independently of their GHD status (Fig. 2). Nine centres declared to follow more than 500 pituitary patients per year (Barcelona, Genoa, Ljubljana, Lyon Marseille, 


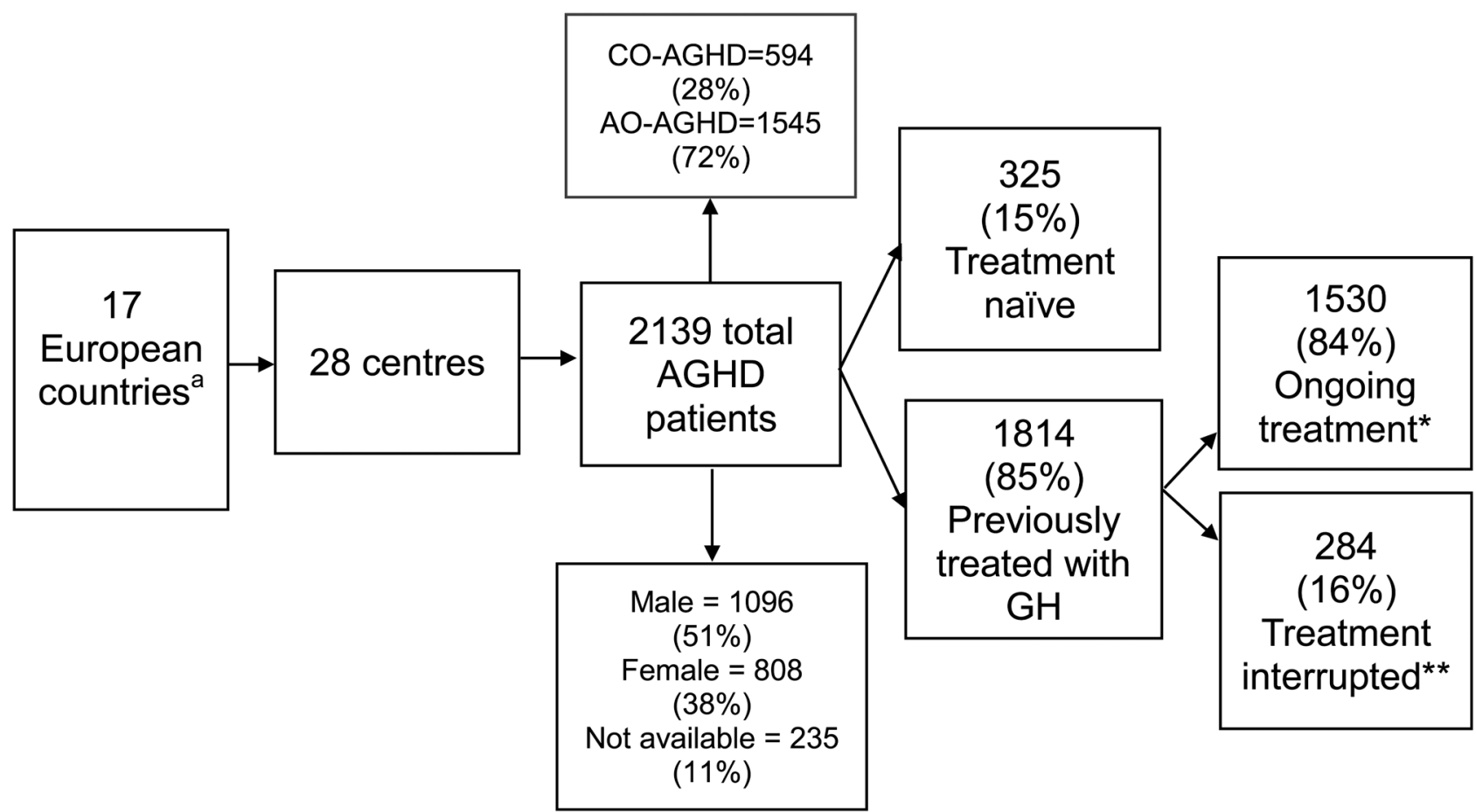

\section{Figure 1}

Number and general characteristics of countries, centres and patients involved in the study. ${ }^{2}$ Countries: Bulgaria, Croatia, Denmark, France, Greece, Hungary, Italy, Lithuania, Portugal, Romania, Serbia, Slovakia, Slovenia, Spain, Sweden, Switzerland, United Kingdom. * GH treatment ongoing at survey initiation (January 1, 2017). **Prior GH therapy received, but interrupted at survey initiation (January 1, 2017). CO-AGHD, childhood-onset adult growth hormone deficiency; AO-AGHD, adult-onset adult growth hormone deficiency.

Table 1 Estimated and captured prevalence of patients with adult growth hormone deficiency (AGHD) per country from reference (1).

\begin{tabular}{|c|c|}
\hline Countries & $\begin{array}{l}\text { Population (million } \\
\text { inhabitants) }\end{array}$ \\
\hline Bulgaria & 7 \\
\hline Croatia & 4 \\
\hline Denmark & 5 \\
\hline France & 66 \\
\hline Greece & 10 \\
\hline Hungary & 10 \\
\hline Italy & 60 \\
\hline Lithuania & 3 \\
\hline Portugal & 10 \\
\hline Romania & 19 \\
\hline Serbia & 7 \\
\hline Slovakia & 5 \\
\hline Slovenia & 2 \\
\hline Spain & 46 \\
\hline Sweden & 10 \\
\hline Switzerland & 9 \\
\hline UK & 66 \\
\hline
\end{tabular}

\begin{tabular}{c}
$\begin{array}{c}\text { Estimated AGHD } \\
\text { patients }\end{array}$ \\
\hline 1225 \\
700 \\
875 \\
11550 \\
1750 \\
1750 \\
10500 \\
525 \\
1750 \\
3325 \\
1225 \\
875 \\
350 \\
8050 \\
1750 \\
1575 \\
11550
\end{tabular}

\begin{tabular}{c}
$\begin{array}{c}\text { AGHD patients } \\
\text { captured }\end{array}$ \\
\hline 87 \\
25 \\
281 \\
206 \\
28 \\
45 \\
622 \\
10 \\
65 \\
83 \\
30 \\
67 \\
70 \\
192 \\
254 \\
18 \\
91
\end{tabular}

Percentage of captured AGHD patients based on estimated number of patients (\%)

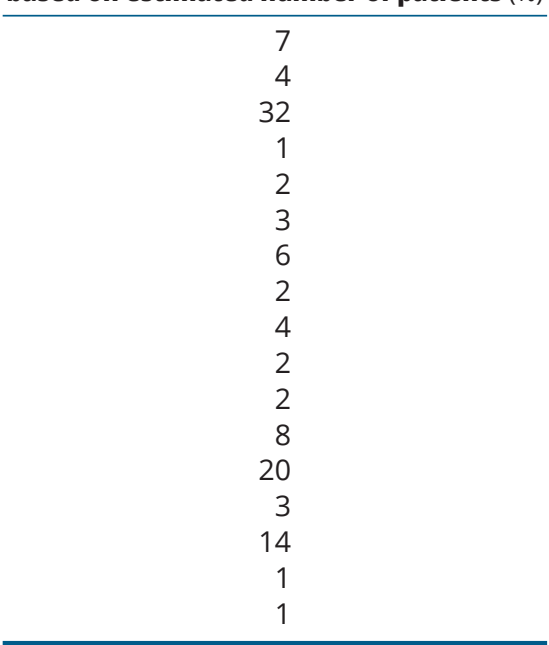


A

口Pituitary surgeries $\quad$ Pituitary radiotherapies $\quad$ AGHD patients

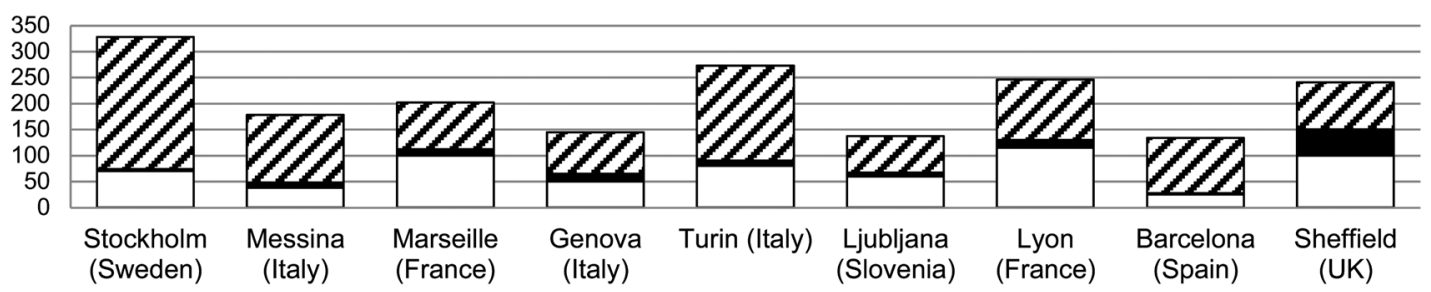

\begin{tabular}{|ccccccccccc} 
AGHD patients & 254 & 130 & 90 & 80 & 183 & 70 & 116 & 106 & 87 \\
$\begin{array}{c}\text { Pituitary } \\
\text { radiotherapy }\end{array}$ & 4 & 10 & 12 & 15 & 10 & 7 & 15 & 3 & 3 \\
Pituitary surgeries & 70 & 38 & 100 & 50 & 80 & 60 & 115 & 25 & 100 \\
Pituitary patients & 2000 & 1200 & 1050 & 1000 & 1000 & 930 & 910 & 630 & 500 \\
\hline
\end{tabular}

B

口Pituitary surgeries

- Pituitary radiotherapies

चGHD patients

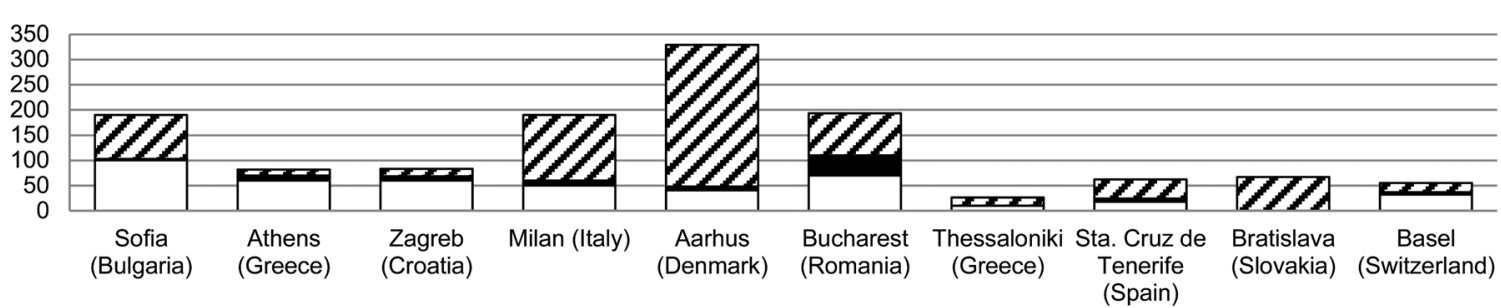

\begin{tabular}{|cccccccccccc|}
\hline AGHD patients & 87 & 12 & 15 & 130 & 280 & 83 & 16 & 38 & 67 & 18 \\
$\begin{array}{c}\text { Pituitary } \\
\text { radiotherapy }\end{array}$ & 3 & 10 & 8 & 10 & 8 & 40 & 0 & 6 & 0 & 5 \\
$\begin{array}{c}\text { Pituitary } \\
\begin{array}{c}\text { surgeries } \\
\text { Pituitary }\end{array} \\
\text { patients }\end{array}$ & 100 & 60 & 60 & 50 & 40 & 70 & 10 & 18 & 0 & 32 \\
\hline
\end{tabular}

C

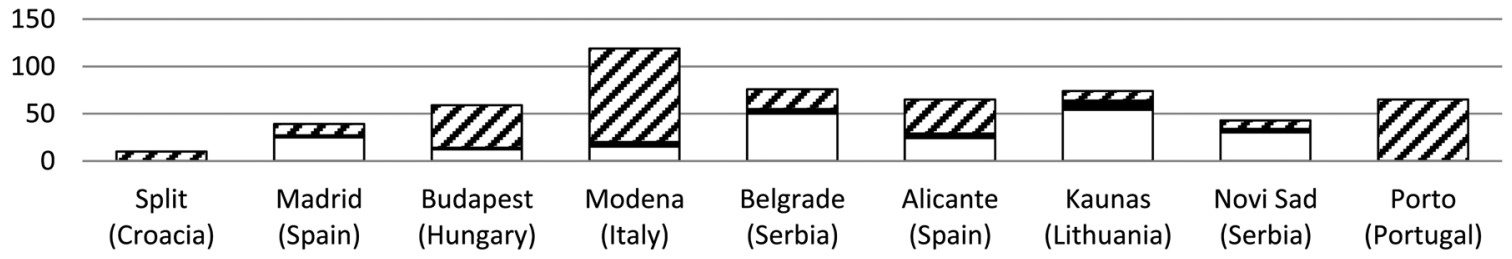

\begin{tabular}{|cccccccccc|}
\hline AGHD patients & 10 & 12 & 45 & 99 & 21 & 36 & 10 & 9 & 65 \\
$\begin{array}{c}\text { Pituitary } \\
\text { radiotherapy }\end{array}$ & 0 & 2 & 2 & 5 & 5 & 5 & 10 & 4 & $?$ \\
$\begin{array}{c}\text { Pituitary } \\
\begin{array}{c}\text { surgeries } \\
\text { Pituitary patients }\end{array}\end{array}$ & 0 & 25 & 12 & 15 & 50 & 24 & 54 & 30 & $?$ \\
\hline
\end{tabular}

\section{Figure 2}

Number of pituitary patients and identified AGHD patients followed and pituitary surgeries and pituitary radiotherapies performed on average per year in each centre. (A) Centres that follow $\geq 500$ pituitary patients; (B) centres that follow <500 to $>100$ pituitary patients; (C) centres that follow $\leq 100$ patients. AGHD, adult growth hormone deficiency. 
Messina, Sheffield, Stockholm and Turin), another 10, between 100 and 500 patients (Aarhus, Athens, Basel, Bratislava, Bucharest, Milan, Sophia, Tenerife, Thessaloniki, Zagreb) and the remaining, 100 patients or less per year (between 20 and 100).

The aetiology of AGHD and the degree of hypopituitarism are shown in Table 2 . The most common cause of AGHD was a non-functioning pituitary adenoma ( $26 \%$ of all cases reported), followed by craniopharyngioma and genetic or congenital midline malformations (13\% each). Only 4\% had isolated GHD; $22 \%$ had diabetes insipidus and most patients had additional pituitary hormone deficiencies.

Twenty-eight per cent $(n=594)$ corresponded to patients with childhood-onset AGHD (CO-AGHD); among those with adult-onset AGHD (AO-AGHD), age of diagnosis was from 18 to 25 years in $10 \%$; between 26 and 45 years in 29\%; 46-65 years in 28\%; and older than

Table 2 Aetiology of adult growth hormone deficiency (AGHD) and the degree of hypopituitarism in the patient cohort.

\begin{tabular}{|c|c|c|}
\hline & No of patients $(n=2139)$ & $\%$ \\
\hline \multicolumn{3}{|l|}{ Aetiology of AGHD } \\
\hline $\begin{array}{l}\text { Non-functioning } \\
\text { pituitary adenoma }\end{array}$ & 555 & 26 \\
\hline Craniopharyngioma & 285 & 13 \\
\hline $\begin{array}{l}\text { Genetic/congenital } \\
\text { midline malformations }\end{array}$ & 282 & 13 \\
\hline $\begin{array}{l}\text { Other pituitary mass } \\
\text { lesions (including cysts, } \\
\text { inflammatory) }\end{array}$ & 172 & 8 \\
\hline Prolactinoma & 134 & 6 \\
\hline $\begin{array}{l}\text { Cranial irradiation due } \\
\text { to another malignant } \\
\text { disease }\end{array}$ & 117 & 6 \\
\hline Cushing's syndrome & 94 & 4 \\
\hline $\begin{array}{l}\text { Vascular causes } \\
\text { (Sheehan's syndrome, } \\
\text { apoplexy, etc.) }\end{array}$ & 82 & 4 \\
\hline Idiopathic isolated GHD & 81 & 4 \\
\hline Traumatic brain injury & 57 & 3 \\
\hline Treated acromegaly & 50 & 2 \\
\hline Other & 143 & 7 \\
\hline Not known & 82 & 4 \\
\hline \multicolumn{3}{|l|}{ Other pituitary deficiencies* } \\
\hline $\begin{array}{l}\text { No other pituitary } \\
\text { deficiency }\end{array}$ & 162 & 8 \\
\hline TSH deficiency & 1754 & 82 \\
\hline LH/FSH deficiency & 1622 & 76 \\
\hline ACTH deficiency & 1491 & 70 \\
\hline ADH deficiency & 467 & 22 \\
\hline PRL deficiency & 150 & 7 \\
\hline
\end{tabular}

*Centres were allowed to choose more than one deficiency per patient. $\mathrm{ACTH}$, adrenocorticotrophin hormone; $\mathrm{ADH}$, antidiuretic hormone; $\mathrm{FSH}$, follicle-stimulating hormone; GHD, growth hormone deficiency; LH, luteinising hormone; $\mathrm{PRL}$, prolactin; $\mathrm{TSH}$, thyroid stimulation hormone.
65 years, less than 5\%. Distribution of age at GH treatment initiation was similar (<18 years-old: $22 \% ; 18-25$ years-old: 13\%; 26-45 years old: 31\%; 46-65 years old: 30\%; >65 years old: $4 \%$ ), indicating that, in general, there was no delay in treatment initiation after the diagnosis of GHD.

As far as the tests used to diagnose AGHD, 1103 patients (52\%) underwent a stimulation test, mainly a GHRH+arginine test $(45 \%)$ or an insulin tolerance test (ITT) (42\%); in 6\% a glucagon test was performed and other tests in another 7\% including GHRH alone and clonidine. Fourteen per cent $(n=305)$ of patients did not undergo any GH stimulation test but were diagnosed on the basis of 3 or more other pituitary deficiencies plus a low serum IGF-I (reported in 54\% of the centres to be enough to diagnose AGHD). In the remaining 34\% $(n=731)$ of patients, information on stimulation tests was unavailable. Figure 3 depicts the diagnostic test preference in specific clinical situations when a test was either clinically contraindicated or was of limited diagnostic accuracy.

When all other endocrine axes are normal, 34\% of centres do not perform a stimulation test even if an underlying pituitary disease exists, since it is not an indication for substitution therapy in many countries.

The diagnostic cut-off for the ITT test used to diagnose GH deficiency was $<3 \mu \mathrm{g} / \mathrm{L}$, except for three centres which used the cut-off $<5 \mu \mathrm{g} / \mathrm{L}$ (Bratislava, Madrid and Sheffield). The diagnostic cut-off for the GHRH+arginine test was $<9$ $\mu \mathrm{g} / \mathrm{L}$ in Italy in patients with a BMI $<30 \mathrm{~kg} / \mathrm{m}^{2}$ and $<4$ $\mu \mathrm{g} / \mathrm{L}$ in patients with a BMI $\geq 30 \mathrm{~kg} / \mathrm{m}^{2}$ and $<6 \mu \mathrm{g} / \mathrm{L}$ in Denmark, irrespective of BMI, while in other countries (Romania, Sweden, Switzerland and United Kingdom) a peak of $<11,<8$ or $<4$ was considered diagnostic of AGHD when BMI is $<25,25-30$, or $>30 \mathrm{~kg} / \mathrm{m}^{2}$, respectively. Twothirds of the centres (18/28) required IGF-I to be low to initiate $\mathrm{GH}$ therapy, while this was not necessary for the remaining 10 centres.

When considering GH substitution therapy, patient compliance and symptoms (i.e. impaired quality of life and severe fatigability) were important determinants for initiating treatment (Table 3); age under 65 years and central obesity, however, were only considered by $11 \%$ of participating centres. Administrative issues (i.e. lack of reimbursement and restrictions to provide the drug in hospital pharmacies) were the main reason why GH therapy was not initiated in countries like Romania (100\% of untreated patients), Portugal and Greece (90\%), Lithuania (70\%) and Bulgaria (60\%). After diagnosis of AGHD and no coexistent contraindications, treatment was begun in some but not all centres (Fig. 4). As far as the 


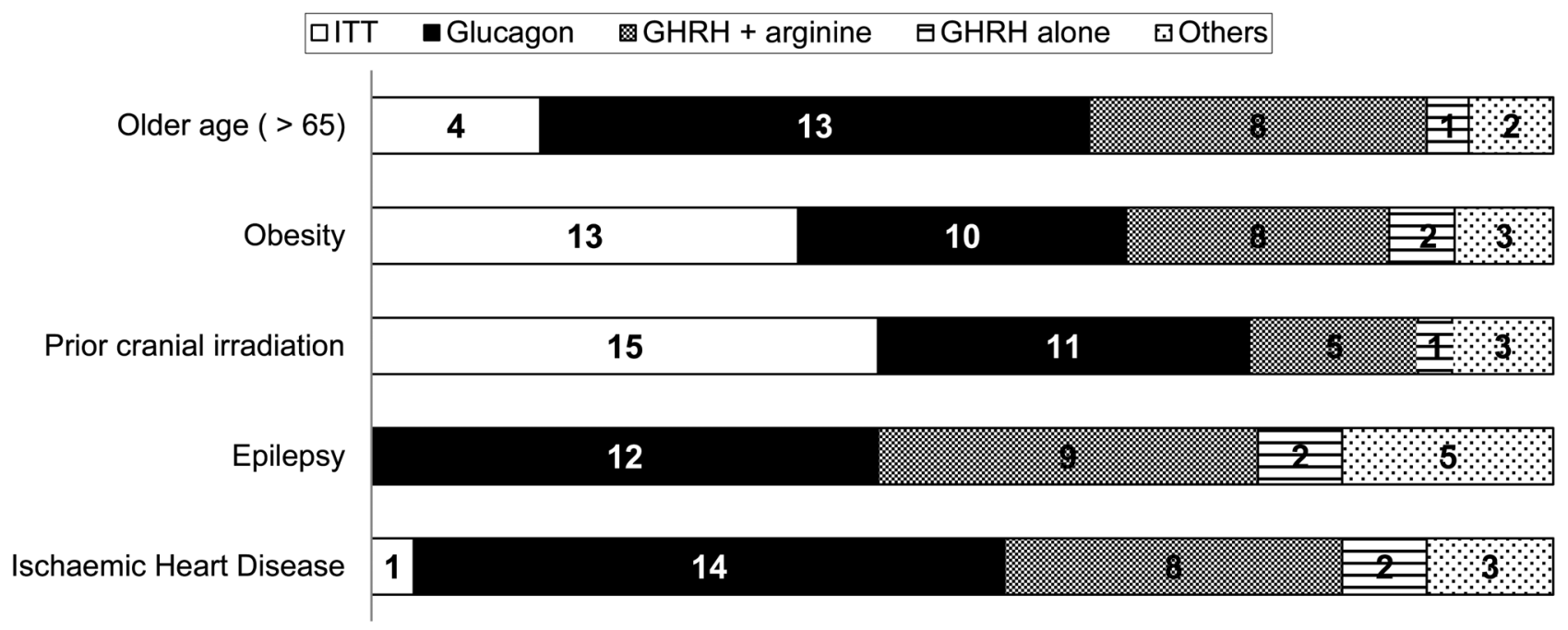

\section{Figure 3}

Number of centres that chose to perform different stimulation tests in specific situations. Centres were allowed to choose more than one test per each situation. ITT, Insulin tolerance test; GHRH, growth hormone-releasing hormone.

starting dose of $\mathrm{GH}, 0.3 \mathrm{mg} /$ day was most often prescribed as first choice in those aged $26-45$ years, and $0.2 \mathrm{mg} /$ day in those aged 46 to above 65 years, irrespective of gender. However, in patients aged 25 years or younger, higher doses were prescribed in women $(0.75 \mathrm{mg} /$ day if $<18$ years and $0.5 \mathrm{mg} /$ day if aged between 18 and 25) than in men

Table 3 Features considered when initiating growth hormone $(\mathrm{GH})$ substitution therapy. Data is presented as $n(\%)$.

\begin{tabular}{|c|c|c|}
\hline & $\begin{array}{l}\text { Centres } \\
(n=28)\end{array}$ & $\begin{array}{l}\text { Patients } \\
(n=2139)\end{array}$ \\
\hline \multicolumn{3}{|l|}{$\begin{array}{l}\text { Requirements for } \mathrm{GH} \\
\text { treatment initiation* }\end{array}$} \\
\hline Patient compliance & $21(75)$ & \\
\hline Impaired quality of life & $12(43)$ & \\
\hline Severe fatigability & $9(32)$ & \\
\hline Age $<65$ years & $3(11)$ & \\
\hline Central obesity & $3(11)$ & \\
\hline Others** & $2(7)$ & \\
\hline \multicolumn{3}{|l|}{ 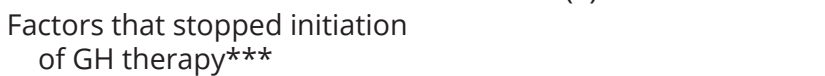 } \\
\hline Administrative issues & & $220(10)$ \\
\hline Compliance considerations & & $119(6)$ \\
\hline $\begin{array}{l}\text { Persistent and stable pituitary } \\
\text { tumour rests }\end{array}$ & & $96(4)$ \\
\hline Age $>65$ years & & $52(2)$ \\
\hline Concomitant diabetes mellitus & & $20(1)$ \\
\hline Other & & $141(7)$ \\
\hline None & & $1270(59)$ \\
\hline
\end{tabular}

(0.2 mg/day). In Portugal, the initial dose was prescribed according to the patient's body weight.

Most recommended administering $\mathrm{GH}$ injections in the evening (60\%) and considered a switch from oral to transdermal or transvaginal oestrogens $(10 \%)$, increased monitoring for patients >65 years old $(4 \%)$, checking of free $\mathrm{T} 4$ when taking thyroxin replacement therapy $(57 \%)$ and considering an increase in hydrocortisone replacement dose $(26 \%)$.

In 284 patients, GH substitution had been interrupted at the time of the survey. The causes of GH treatment interruption are shown in Table 4. Adverse events were responsible in $57 \%$ of the cases, while lack of compliance, administrative reasons and lack of perceived improvement while on therapy, and death (4\%) were also reported.

As far as the transitioning from childhood to adult care, the age was $>18$ years in 19 centres and between 14 and 18 years in another 8 centres (this information was missing in the remaining centre). Most of the CO-AGHD patients were referred by the paediatrician or another practitioner to adult care (68\%), although $17 \%$ were seen after direct patient inquiry. In the remaining (15\%), this information was unavailable. In 224/594 CO-AGHD patients, GH substitution was interrupted during transitioning to adult care for more than 24 months ( $n=157)$. The reasons for $\mathrm{GH}$ treatment interruption during transition to adult care are shown in Table 5. While lack of reimbursement and patients own decision to stop $\mathrm{GH}$ treatment was the most frequent reason for treatment interruption, discharge by the paediatric 


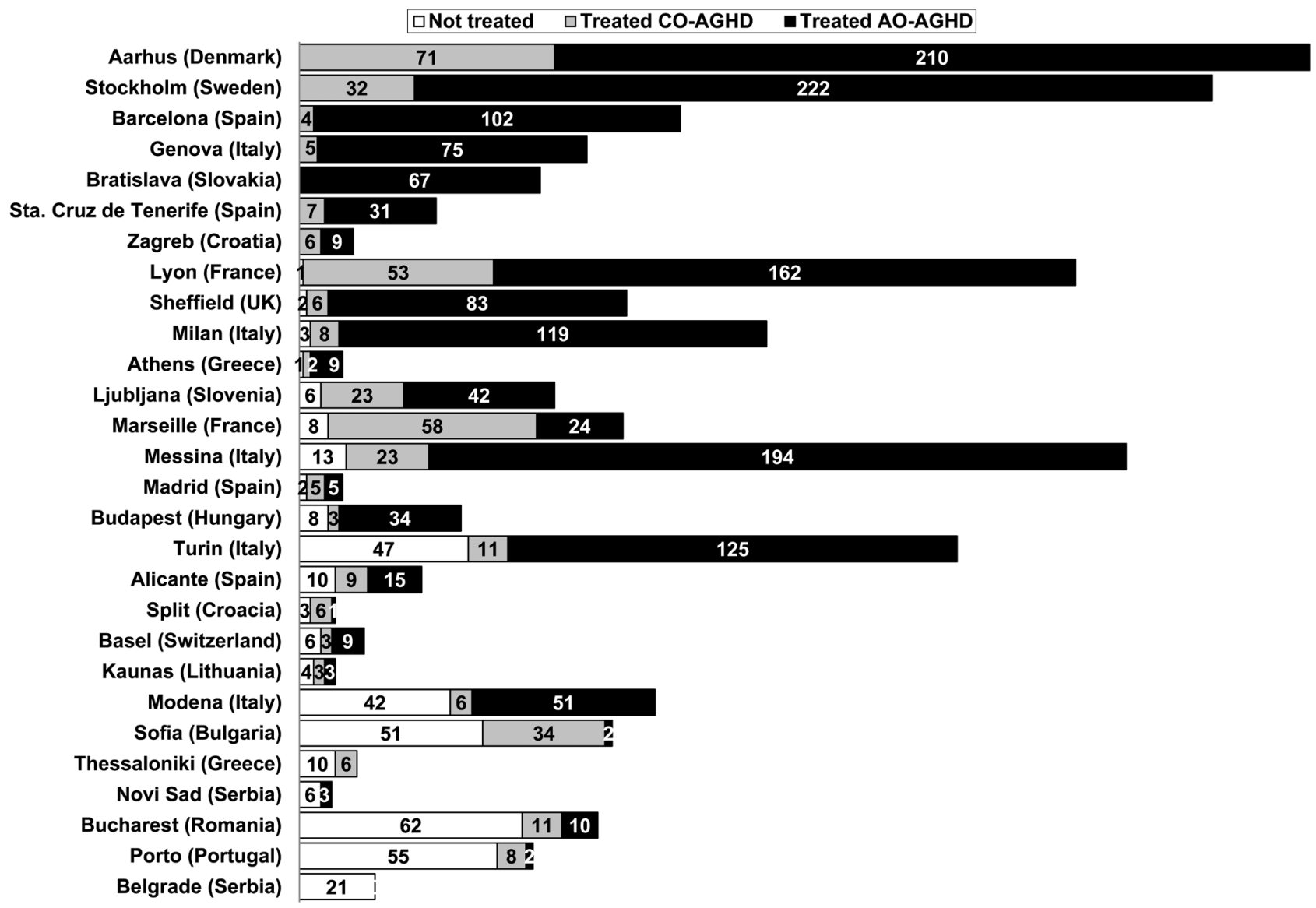

\section{Figure 4}

Number of patients diagnosed with adult growth hormone deficiency (AGHD), who were either treated or not with growth hormone in each centre. CO-AGHD, childhood-onset AGHD; AO-AGHD, adult-onset AGHD.

consultant or poor patient compliance and difficulty in referral to an adult clinic were also reported.

As far as follow-up after starting GH therapy, half the centres measured IGF-I 2-3 months after initiating treatment and every 12 months once a stable dose was reached. Considering the targeted IGF-I concentration to be reached during treatment, $40 \%$ aimed at a value within the normal range, $26 \%$ within the mid-normal range, $14 \%$ aimed at a high-normal range, and 3\% aimed at a low-normal range. Other variables used for GH dose titration, were body weight: $62 \%(1319 / 2139), \mathrm{HbA1c}$ : 60\% (1284/2139), blood pressure: 58\% (1245/2139), BMI: 58\% (1240/2139), total cholesterol: 56\% (1203/2139), high-density lipoprotein (HDL): 52\% (1223/2139), low-density lipoprotein (LDL): 47\% (1006/2139), bone mineral density: 41\% (876/2139), waist circumference: $34 \%$ (728/2139), and body fat: 13\% (270/2139). Overall wellbeing and energy level was regularly asked for in $61 \%$ of patients, while the number of sick day leave and partner satisfaction in less than 11\%. A specific quality of life (QoL) questionnaire was administered for treatment monitoring in $45 \%$ of AGHD patients. The most commonly used were The QoL Assessment of GH Deficiency Adults questionnaire (QoL-AGHDA) and the Questions on Life Satisfaction Hypopituitarism Module (QLS-H) $(21,22)$. In 2\%, a generic questionnaire was used (SF-36).

When asked whether a pituitary MRI was performed at initial evaluation, in $84 \%$ of the patients the answer was positive; in $10 \%$ this information was unavailable and in $6 \%$ the answer was negative; whether a CT scan was performed in these latter patients was not collected. Additionally, most centres performed new MRIs 6-12 months after initiating GH treatment (85\%) in patients with residual tumour, and after 12 months in patients without residual tumour.

In Romania, the indication of GH treatment for AGHD is not reimbursed. In Lithuania and Portugal, full public 
Table 4 Causes of growth hormone treatment interruption in adult growth hormone deficiency patients.*

\begin{tabular}{|c|c|c|}
\hline & Number of patients $(n=284)$ & $\%$ \\
\hline Adverse events & 162 & 57 \\
\hline New cancer & 36 & 12 \\
\hline Tumour recurrence & 25 & 9 \\
\hline Fluid retention/oedema & 16 & 6 \\
\hline Arthromyalgia & 13 & 8 \\
\hline Hyperglycaemia & 9 & 5 \\
\hline Headache & 0 & 0 \\
\hline Other & 63 & 22 \\
\hline Lack of compliance & 61 & 22 \\
\hline Administrative reasons & 54 & 19 \\
\hline $\begin{array}{l}\text { Lack of positive effect } \\
\text { perceived by the patient }\end{array}$ & 51 & 18 \\
\hline Death & 12 & 4 \\
\hline Not specified & 106 & 37 \\
\hline
\end{tabular}

*Centres were able to choose more than one cause for treatment interruption per patient.

reimbursement was approved only recently (2018-2019), whereas, in Slovakia, reimbursement is partial. In Greece, despite approval, hospital pharmacies are reluctant to supply GH, while in Bulgaria full public reimbursement is only approved in CO-AGHD. In Hungary, only those endocrinologists who work at accredited GH centres are able to prescribe GH substitution.

As far as the dispensation of the drug, it was most frequently dispensed in regional or reference hospital pharmacies (18/28), while in the others it was dispensed in the local pharmacy. In two countries (United Kingdom and Sweden) patients had the option of receiving their $\mathrm{GH}$ at home, via a registered online delivery service.

The level of satisfaction regarding available education and training resources and AGHD management in each local setting is shown in Fig. 5. While the greatest level of satisfaction was in the extent and quality of nurse training,

Table 5 Causes of growth hormone treatment interruption in childhood-onset adult growth hormone deficiency during transition to adult care.*

\begin{tabular}{|c|c|c|}
\hline & Number of patients $(n=224)$ & $\%$ \\
\hline Lack of reimbursement & 75 & 33 \\
\hline $\begin{array}{l}\text { Patient electing to stop the } \\
\text { treatment }\end{array}$ & 68 & 30 \\
\hline $\begin{array}{l}\text { Discharge by the paediatric } \\
\text { consultant }\end{array}$ & 29 & 13 \\
\hline Poor patient compliance & 15 & 7 \\
\hline $\begin{array}{l}\text { Difficulty in referral to an } \\
\text { adult clinic }\end{array}$ & 5 & 2 \\
\hline Not known/not answered & 146 & 64 \\
\hline
\end{tabular}

*Centres were able to choose more than one cause for treatment interruption per patient. dissatisfaction was high in relation to AGHD awareness by non-endocrine healthcare professionals; additionally, there was room for improvement in the curriculum of postgraduate training related to AGHD.

When the centres with a higher percentage of patients under GH treatment were compared to those with a lower percentage, a correlation was observed with a higher level of satisfaction in overall quality of AGHD treatment in the formers $(P=0.005)$. Not surprisingly, where full public treatment reimbursement was available, more GH treatments were prescribed $(P=0.020)$. Also, the level of satisfaction with the overall quality of AGHD patient treatment in each setting correlated with full public reimbursement of GH therapy $(P=0.018)$.

\section{Discussion}

We report data from a survey on current practice of AGHD management across Europe and benchmarked these reallife data with pertinent guidelines $(17,18,19,20)$.

Underlying diagnoses of hypothalamic-pituitary disease was congruent with the guidelines. Only 81/2139 (4\%) patients with idiopathic isolated adult-onset GHD were reported, an entity not recognised as occurring de novo in adults (17).

As far as diagnostic tests, stimulation tests not considered valid in adults, such as GHRH alone or clonidine, were used in certain centres (17). Regarding the ITT diagnostic threshold for AGHD, most centres followed the European consensus of $<3 \mu \mathrm{g} / \mathrm{L}$ (17), although Bratislava, Madrid and Sheffield accepted the Endocrine Society consensus of $<5 \mu \mathrm{g} / \mathrm{L}$ (20). In contrast with the guidelines, BMI-dependent cut-off values were not always considered for the GHRH+arginine test (17). A low baseline IGF-I level was required to start GH therapy in two-thirds of the centres, despite that the guidelines state that a normal IGF-I does not rule out GHD at any age.

Administrative reasons contributed to treatment interruption during transition, since AGHD is not an approved indication for $\mathrm{GH}$ therapy reimbursement in Romania; in Lithuania and Portugal, reimbursement for AGHD was only recently approved. In Slovakia reimbursement is only partial, and in Greece hospital pharmacies are reluctant to supply treatment for budget reasons despite approval of the indication. In Bulgaria, full public reimbursement is only approved for adults if they are diagnosed as CO-AGHD. Finally, in Hungary, only endocrinologists who work at accredited GH centres are allowed to prescribe reimbursed GH substitution for 


\section{घVery satisfied $\square$ Satisfied $\square$ Neither Satisfied nor Dissatisfied $\quad$ DDissatisfied $\quad$ Very dissatisfied}

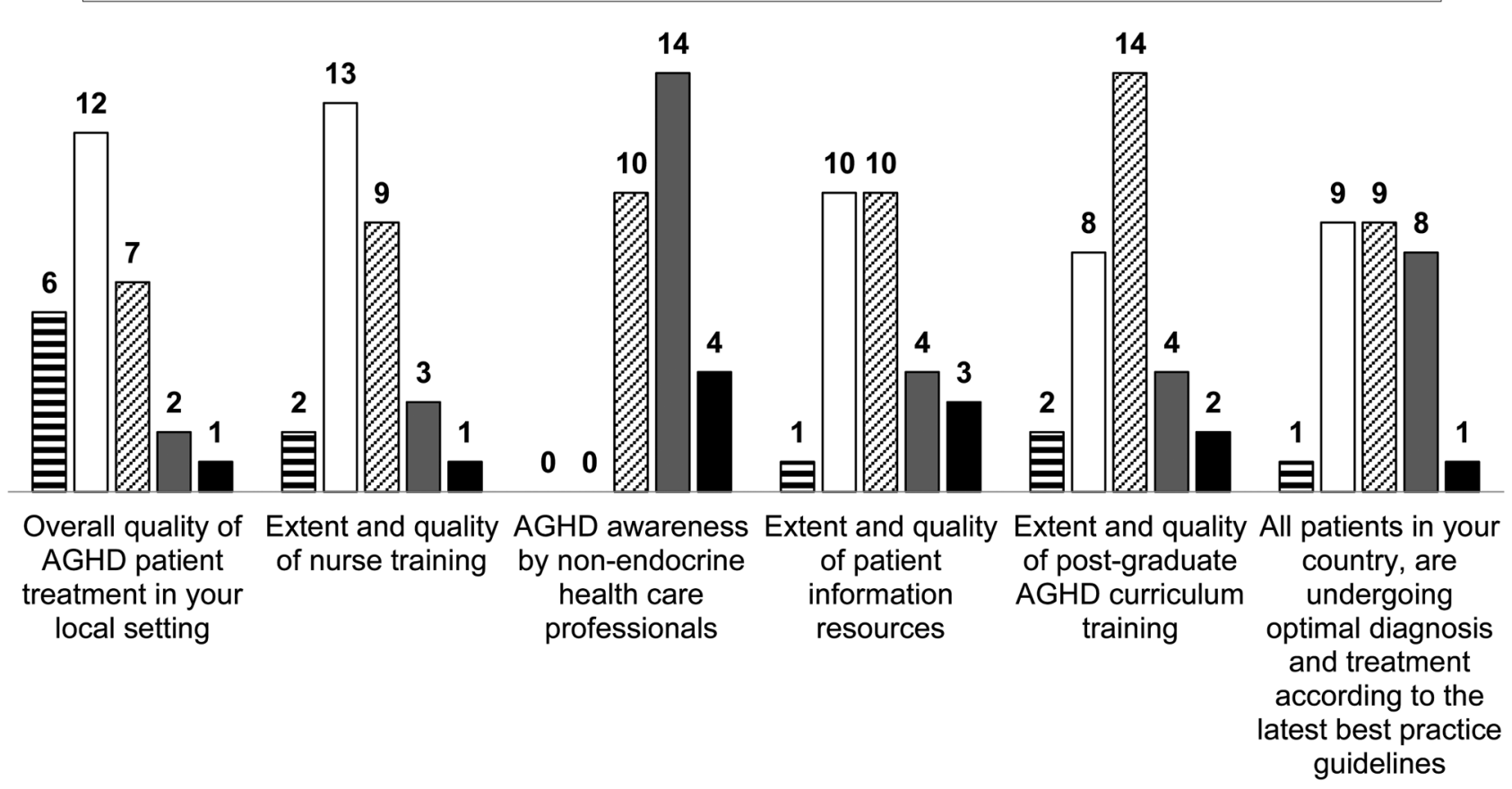

\section{Figure 5}

Level of satisfaction across centres $(n=28)$. AGHD, adult growth hormone deficiency.

adults. Other reported reasons for stopping GH treatment at transition included patient preference, lost to follow-up and poor patient compliance.

Not all centres reported data on non-treated AGHD patients, especially in countries where most are offered therapy after diagnosis. In fact, the guidelines state that AGHD should be confirmed if treatment is a possibility. Thus, eligible patients in whom GH therapy was not initiated were not reported in many centres. Additionally, some patients with organic isolated AGHD could be underdiagnosed and therefore not reported, since up to a third of centres do not perform stimulation tests when the rest of the endocrine axes are normal; this is in line with the regulation in many countries, where GH treatment is not indicated in these cases. Even though the decision to treat AGHD requires a detailed evaluation of potential risks and benefits by knowledgeable healthcare providers, evidence is now convincing of the benefits of GH replacement therapy, especially if symptomatic and in young adults with persistent GHD after attaining final height, since it enables full somatic development, accrual of maximal bone and muscle mass, and improvement persists during chronic treatment (17).

Only in patients $<25$ years did women receive higher doses than men, as stated in the guidelines. After 26 years, starting doses declined with age, but no gender differences in dosing were reported. In Portugal, GH dose was prescribed based on body weight, although this is not recommended in the guidelines (17). Most centres recommended $\mathrm{GH}$ to be administered in the evening, mimicking the greater nocturnal secretion, but this was not the case in over $40 \%$ of patients. Dose was initially adjusted after 2-3 months based on IGF-I concentration and clinical response, and on an annual basis thereafter; additionally, most centres considered adjusting the dose of other pituitary replacement therapies. However, it was surprising that only $10 \%$ considered switching oral oestrogens to a transdermal or transvaginal route, given the inhibitory effect of oral oestrogens on hepatic synthesis of IGF-I (17).

Treatment interruption due to adverse events, lack of compliance or perceived benefit, as well as administrative reasons were as expected. Twelve deaths were reported ( $0.56 \%$ of the 2139 patients), but it is not known whether any was related to GH therapy.

As far as safety during $\mathrm{GH}$ treatment, both at baseline and follow-up, pituitary MRIs were performed for safety as suggested in the guidelines; however, in long-term follow-up, interval between subsequent imaging depended on the underlying diagnosis and treatment received, that is, after radiotherapy, the interval between imaging was prolonged in some centres. 
For efficacy, the guidelines state that IGF-I should be maintained within the age- and gender-related normal range, also if IGF-I was normal $(17,20)$ and this was evidenced in $83 \%$ of the patients in whom information was available. Other efficacy variables reported in approximately half the patients, were BMI and waist circumference, haemoglobin A1c, and surrogate biomarkers of cardiovascular risk including blood pressure and lipids.

Finally, attentive questioning to assess quality of life, energy level, partner satisfaction, sick day leave and vitality, to monitor treatment response during follow up, was often not contemplated, although considered essential (17). Overall wellbeing and energy level were routinely questioned in only $61 \%$, while the number of sick days and partner satisfaction were recorded in less than $11 \%$.

Good patient compliance, and to a lesser extent, impaired QoL and severe fatigue were considered before initiating GH therapy (23). In 10\%, administrative issues (mostly lack of reimbursement) prevented GH therapy, whereas tumour remnants, patient age $>65$ years or diabetes mellitus prevented treatment in $<5 \%$ of patients.

In the United Kingdom, impaired baseline QoL using the AGHDA questionnaire is a prerequisite to initiate GH substitution (21), and QoL is supposed to improve. In other countries, however, QoL questionnaires are not used, which is in accordance with the guidelines.

Growth hormone was predominantly provided by hospital pharmacies, which in some centres was enforced to prevent illicit use of the drug (20) or in order to reduce costs. Only in some countries, were central data collection of GH treated patients in place, allowing health authorities to evaluate its scope and cost.

Eighteen out of the 28 participating centres were satisfied with the overall quality of AGHD patients' management, and especially with the extent and quality of nurse training. Not surprisingly, the degree of satisfaction was higher in centres that treated more patients than in those with less experience.

The global cost of orphan drugs for the 7 to 8 thousand rare diseases is around 5\% of the global pharmaceutical expenditure in countries such as The Netherlands, France, Sweden and in Catalonia ('Report on evaluation of results: Treatment of rare disease with individually authorised drugs in the year 2019'. Barcelona. Catalan Health System. Department of Health. Generalitat of Catalonia; 2020. Accessed August 24, 2020, via: https:/canalsalut.gencat .cat/ca/salut-a-z/m/malalties_minoritaries/tractament). The contribution to this expense of substitution therapy with $\mathrm{GH}$ is minimal. Based on the results of this survey, this gap is an opportunity for a joint effort, of the ESE and the National
Societies to raise awareness around AGHD, not just in the medical community but primarily also to health policy officials and funding bodies. Including this topic in the ESE pan-European curriculum for Endocrinology, Metabolism and Diabetes is also desirable $(2,3,24,25,26)$. Improvement of perceived health with GH therapy, as well as long-term outcome and quality of life with optimal substitution therapy in hypopituitary patients, are strong arguments to offer treatment to eligible patients (27). Sharing experience with other patients can be very helpful (28).

Among the limitations of this survey is the variable participation in different countries, reaching a third of estimated patients in Denmark, one-fifth in Slovenia, and $14 \%$ in Sweden, but less than 5\% of the populationbased estimation of AGHD patients in 12 countries. Some large countries, such as Germany, did not participate. Considering the gap between the estimated and captured AGHD patients across Europe, this disease is more prevalent than currently thought in practice and probably not so rare. Centres with less experience in the diagnosis and treatment of AGHD were not included, since it was considered of greater educational value to collect data from centres with at least ten treated patients.

The initial idea of comparing results from European with other countries was not feasible since only one Australian centre provided nine cases; however, it is worth mentioning that at survey initiation in 2017, GH was not reimbursed in Australia, but has now become part of the pharmaceutical benefit scheme. A strength, however, is collecting real-life data from clinical centres responsible for the diagnosis and management of AGHD. Given that the current guidelines were published in 2007 and 2016 and that since then further data on efficacy and safety on GH therapy in AGHD have become available, confirming the benefits of treatment, an update of the guidelines would seem pertinent.

In summary, this ESE-led audit has identified country-specific differences in the diagnosis and management of AGHD patients. Although the guidelines are followed to a large extent, several exceptions were identified. GH substitution in adults does not appear to be a priority among health administrators, despite the fact that the cost of GH treatment in comparison to global health costs is negligible. Despite that nearly 25 years have passed since the initial 1996 Post Stephens AGHD consensus (29), equality of health care in Europe for rare diseases, an aim of both the European Health Directives and EndoERN (the European Reference Network for Rare Endocrine Diseases) is not globally guaranteed for AGHD. To improve the final outcome of AGHD patients; education and a greater alert of 
the advantages of $\mathrm{GH}$ substitution therapy in these deficient patients would seem desirable, including by non-endocrine healthcare providers.

\section{Supplementary materials}

This is linked to the online version of the paper at https://doi.org/10.1530/ EJE-20-1180.

\section{Declaration of interest}

The authors declare that there is no conflict of interest that could be perceived as prejudicing the impartiality of this study.

\section{Funding}

This work was funded by a Pfizer Independent Grant for Learning \& Change: (IGLC): ID 9939445

\section{Acknowledgements}

The authors wish to acknowledge the contribution in data collection and thank Haifa Rahabi-Layachi and Aude Bourgeois-André from Assistance Publique-Hôpitaux de Marseille (AP-HM), Hôpital de la Conception, Marseille, and Aix-Marseille Université, U1251, Marseille Medical Genetics (MMG), France and Marta Franco from Endocrinology Unit, Department of Internal Medicine and Medical Specialties (DIMI), University of Genoa, Genoa, Italy. Technical support to design the forms for data collection was provided by Lohmann \& Birkner (Berlin), and the specific discussions and insight of Holger Franz is gratefully acknowledged. Without the contribution of Nik Screen in applying to the Independent Learning \& Change call, this survey would not have been possible. The helpful discussions and suggestions of Dirk de Rijdt are very much appreciated.

The ESE AGHD study Group is formed by F Adamidou and G Mintziori, Department of Endocrinology \& Metabolism, Hippokration General Hospital of Thessaloniki, Thessaloniki, Greece; M Arosio and C Giavoli, Department of Clinical Sciences and Community Health, Endocrine Unit, University of Milan, Fondazione IRCCS Cà Granda Ospedale Maggiore Policlinico, Milan, Italy; C Badiu, National Institute of Endocrinology 'C. Davila', University of Medicine and Pharmacy, Bucharest, Romania; M Boschetti and D Ferone, Endocrinology Unit, IRCCS Ospedale Policlinico San Martino, Genoa, Italy and Endocrinology Unit, Department of Internal Medicine and Medical Specialties (DIMI) and Centre of Excellence for Biomedical Research (CEBR), University of Genoa, and S Ricci Bitti, Endocrinology Unit, DIMI, University of Genoa, Genoa, Italy; T Brue and F Albarel, Assistance Publique-Hôpitaux de Marseille (AP-HM), Hôpital de la Conception, 13005, Marseille, and Aix-Marseille Université, U1251, Marseille Medical Genetics (MMG), France; S Cannavo, Unit of Endocrinology, University Hospital 'G. Martino' and O R Cotta, Department of Human Pathology, University of Messina, Messina, Italy; D Carvalho and D Salazar, Department of Endocrinology, Diabetes and Metabolism Centro Hospitalar Universitário de S. João/Faculty of Medicine, Universidade do Porto, i3S - Instituto de Investigação e Inovação em Saúde, Porto, Portugal; E Christ, Interdisciplinary Endocrinology, ENETS Center of Excellence, Division of Endocrinology, Diabetology and Metabolism, University Hospital of Basel, Basel, Switzerland; M Debono, Department of Endocrinology Sheffield Teaching Hospitals, Sheffield, UK; T Dusek, Department of Endocrinology, University Hospital Center Zagreb, Zagreb, Croatia; R García, Department of Endocrinology, Hospital Gregorio Marañón, Madrid, Spain; E Ghigo and V Gasco, Division of Endocrinology, Diabetes and Metabolism, University of Turin, Turin, Italy; M I Goth, D Olah and L Kovacs, Division of Endocrinology, 2nd Department of Medicine, Health Center, Hungarian Defense Forces, Budapest, Hungary;
C Höybye, Department of Endocrinology, Karolinska University Hospital, Stockholm, Sweden; T Kocjan and K Mlekuš Kozamernik, Department of Endocrinology, Diabetes and Metabolic Diseases, University Medical Centre Ljubljana, Ljubljana, Slovenia and Faculty of Medicine, University of Ljubljana, Ljubljana, Slovenia; M Kužma and Juraj Payer, 5th Department of Internal Medicine, Comenius University Faculty of Medicine and University Hospital Bratislava, Bratislava, Slovakia; M Medic Stojanoska, University of Novi Sad, Faculty of Medicine, Clinic for Endocrinology, Diabetes and Metabolic Disease, Clinical Center of Vojvodina, Novi Sad, Serbia; A Novak and T Miličević, Department of Endocrinology, University Hospital Center Split, Split, Croatia; S Pekic and D Milijic, Clinic for Endocrinology, Diabetes and Diseases of Metabolism, Clinical Center of Serbia \& Medical Faculty, University of Belgrade, Belgrade, Serbia; J Perez Luis, Division of Endocrinology and Nutrition, Hospital Universitario de Canarias, Faculty of Health Sciences, University of La Laguna, Santa Cruz de Tenerife, Spain; A Pico, Endocrinology \& Nutrition Department, Health and Biomedical Research Institute of Alicante (ISABIAL), Hospital General Universitario de Alicante, University Miguel Hernandez, Centro de Investigación Biomédica en Red de Enfermedades Raras (CIBERER, GCV 13), ISCIII, Alicante, Spain; V Preda, Department of Clinical Medicine, Faculty of Medicine and Health Sciences, Macquarie University, Sydney, Australia; G Raverot and F Borson-Chazot, Fédération d'Endocrinologie, Centre de Référence Maladies Rares Hypophysaires (HYPO), Groupement Hospitalier Est, Hôpital Louis Pradel, Lyon, France; V Rochira and M L Monzani, Unit of Endocrinology, Department of Biomedical, Metabolic and Neural Sciences, University of Modena and Reggio Emilia, Modena, Italy and Unit of Endocrinology, Department of Medical Specialties, Azienda Ospedaliero-Universitaria di Modena, Ospedale Civile di Baggiovara, Modena, Italy; K Sandahl, Endocrinology and Internal Medicine, Aarhus University Hospital, Aarhus, Denmark; S Tsagarakis and V Mitravela, Department of Endocrinology, Evangelismos General Hospital, Athens, Greece; S Zacharieva, Department of Endocrinology, Medical University - Sofia, Sofía, Bulgaria; B Zilatiene and R Verkauskiene, Department of Endocrinology and Institute of Endocrinology, Lithuanian University of Health Sciences, Kaunas, Lithuania.

\section{References}

1 Regal M, Páramo C, Sierra SM \& Garci-Mayor RV. Prevalence and incidence of hypopituitarism in an adult Caucasian population in northwestern Spain. Clinical Endocrinology 200155 735-740. (https:// doi.org/10.1046/j.1365-2265.2001.01406.x)

2 Webb SM, Mo D, Lamberts SW, Melmed S, Cavagnini F, Pecori Giraldi F, Strasburger CJ, Zimmermann AG, Woodmansee WW \& International HypoCCS Advisory Board. Metabolic, cardiovascular, and cerebrovascular outcomes in growth hormone-deficient subjects with previous Cushing's disease or non-functioning pituitary adenoma. Journal of Clinical Endocrinology and Metabolism 201095 630-638. (https://doi.org/10.1210/jc.2009-0806)

3 Woodhouse LJ, Mukherjee A, Shalet SM \& Ezzat S. The influence of growth hormone status on physical impairments, functional limitations, and health-related quality of life in adults. Endocrine Reviews 200627 287-317. (https://doi.org/10.1210/er.2004-0022)

4 Barake M, Klibanski A \& Tritos NA. Effects of recombinant human growth hormone therapy on bone mineral density in adults with growth hormone deficiency: a meta-analysis. Journal of Clinical Endocrinology and Metabolism 201499 852-860. (https://doi. org/10.1210/jc.2013-3921)

5 Elbornsson M, Götherström G, Bosæus I, Bengtsson BÅ, Johannsson G \& Svensson J. Fifteen years of GH replacement improves body composition and cardiovascular risk factors. European Journal of Endocrinology 2013168 745-753. (https://doi.org/10.1530/EJE-12-1083)

6 Gardner CJ, Mattsson AF, Daousi C, Korbonits M, KoltowskaHaggstrom M \& Cuthbertson DJ. GH deficiency after traumatic brain 
injury: improvement in quality of life with GH therapy: analysis of the KIMS database. European Journal of Endocrinology 2015172 371-381. (https://doi.org/10.1530/EJE-14-0654)

7 Elbornsson M, Horvath A, Götherström G, Bengtsson BÅ, Johannsson G \& Svensson J. Seven years of growth hormone (GH) replacement improves quality of life in hypopituitary patients with adult-onset GH deficiency. European Journal of Endocrinology 2017176 99-109. (https://doi.org/10.1530/EJE-16-0875)

8 Chikani V, Cuneo RC, Hickman I \& Ho KKY. Growth hormone (GH) enhances anaerobic capacity: impact on physical function and quality of life in adults with GH deficiency. Clinical Endocrinology 201685 660-668. (https://doi.org/10.1111/cen.13147)

9 Mo D, Blum WF, Rosilio M, Webb SM, Qi R \& Strasburger CJ. Ten-year change in quality of life in adults on growth hormone replacement for growth hormone deficiency: an analysis of the hypopituitary control and complications study. Journal of Clinical Endocrinology and Metabolism 201499 4581-4588. (https://doi. org/10.1210/jc.2014-2892)

10 Rochira V, Mossetto G, Jia N, Cannavo S, Beck-Peccoz P, Aimaretti G, Ambrosio MR, Di Somma C, Losa M, Ferone D et al. Analysis of characteristics and outcomes by growth hormone treatment duration in adult patients in the Italian cohort of the Hypopituitary Control and Complications Study (HypoCCS). Journal of Endocrinological Investigation 201841 1259-1266. (https://doi.org/10.1007/s40618-018-0860-x)

11 Newman CB, Carmichael JD \& Kleinberg DL. Effects of low dose versus high dose human growth hormone on body composition and lipids in adults with GH deficiency: a meta-analysis of placebocontrolled randomized trials. Pituitary 201518 297-305. (https://doi. org/10.1007/s11102-014-0571-z)

12 Boschetti M, Agosti S, Albanese V, Casalino L, Teti C, Bezante GP, Brunelli C, Albertelli M \& Ferone D. One-year GH replacement therapy reduces early cardiac target organ damage (TOD) in adult GHD patients. Endocrine 201755 573-581. (https://doi.org/10.1007/s12020-016-0951-4)

13 Ziagaki A, Blaschke D, Haverkamp W \& Plöckinger U. Long-term growth hormone (GH) replacement of adult GH deficiency (GHD) benefits the heart. European Journal of Endocrinology 2019181 79-91. (https://doi.org/10.1530/EJE-19-0132)

14 Gonzalez S, Windram JD, Sathyapalan T, Javed Z, Clark AL \& Atkin SL. Effects of human recombinant growth hormone on exercise capacity, cardiac structure, and cardiac function in patients with adult-onset growth hormone deficiency. Journal of International Medical Research 201745 1708-1719. (https://doi. org/10.1177/0300060517723798)

15 Weaver JU, Monson JP, Noonan K, John WG, Edwards A, Evans KA \& Cunningham J. The effect of low dose recombinant human growth hormone replacement on regional fat distribution, insulin sensitivity, and cardiovascular risk factors in hypopituitary adults. Journal of Clinical Endocrinology and Metabolism 199580 153-159. (https://doi. org/10.1210/jcem.80.1.7829604)

16 Kołtowska-Häggström M, Mattsson AF, Monson JP, Kind P, Badia X, Casanueva FF, Busschbach J, Koppeschaar HPF \& Johannsson G. Does long-term GH replacement therapy in hypopituitary adults with GH deficiency normalise quality of life? European Journal of Endocrinology 2006155 109-119. (https://doi.org/10.1530/eje.1.02176)

17 Ho KKY \& 2007 GH Deficiency Consensus Workshop Participants. Consensus guidelines for the diagnosis and treatment of adults with GH deficiency II: a statement of the GH Research Society in association with the European Society for Pediatric Endocrinology, Lawson Wilkins Society, European Society of Endocrinology, Japan Endocrine Society, and Endocrine Society of Australia. European Journal of Endocrinology 2007157 695-700. (https://doi.org/10.1530/EJE-07-0631)
18 Giustina A, Barkan A, Chanson P, Grossman A, Hoffman A, Ghigo E, Casanueva F, Colao A, Lamberts S, Sheppard M et al. Guidelines for the treatment of growth hormone excess and growth hormone deficiency in adults. Journal of Endocrinological Investigation 200831 820-838. (https://doi.org/10.1007/BF03349263)

19 Cook DM, Yuen KCJ, Biller BMK, Kemp SF, Vance ML \& American Association of Clinical Endocrinologists. American Association of Clinical Endocrinologists Medical Guidelines for clinical practice for growth hormone use in growth hormone-deficient adults and transition patients - 2009 update. Endocrine Practice 200915 (Supplement 2) 1-29. (https://doi.org/10.4158/EP.15.S2.1)

20 Fleseriu M, Hashim IA, Karavitaki N, Melmed S, Murad MH, Salvatori R \& Samuels MH. Hormonal replacement in hypopituitarism in adults: an endocrine society clinical practice guideline. Journal of Clinical Endocrinology and Metabolism 2016101 3888-3921. (https://doi.org/10.1210/jc.2016-2118)

21 McKenna SP, Doward LC, Alonso J, Kohlmann T, Niero M, Prieto L \& Wiren L. The QoL-AGHDA: an instrument for the assessment of quality of life in adults with growth hormone deficiency. Quality of Life Research 19998 373-383. (https://doi. org/10.1023/a:1008987922774)

22 Blum WF, Shavrikova EP, Edwards DJ, Rosilio M, Hartman ML, Marín F, Valle D, van der Lily AJ, Attanasio AF, Strasburger CJ et al. Decreased quality of life in adult patients with growth hormone deficiency compared with general populations using the new, validated, selfweighted questionnaire, questions on life satisfaction hypopituitarism module. Journal of Clinical Endocrinology and Metabolism $2003 \mathbf{8 8}$ 4158-4167. (https://doi.org/10.1210/jc.2002-021792)

23 Attanasio AF, Bates PC, Ho KKY, Webb SM, Ross RJ, Strasburger CJ, Bouillon R, Crowe B, Selander K, Valle D et al. Human growth hormone replacement in adult hypopituitary patients: long-term effects on body composition and lipid status - 3-year results from the HypoCCS Database. Journal of Clinical Endocrinology and Metabolism 200287 1600-1606. (https://doi.org/10.1210/jcem.87.4.8429)

24 Valassi E, Franz H, Brue T, Feelders RA, Netea-Maier R, Tsagarakis S, Webb SM, Yaneva M, Reincke M, Droste M et al. Diagnostic tests for Cushing's syndrome differ from published guidelines: data from ERCUSYN. European Journal of Endocrinology 2017176 613-624. (https://doi.org/10.1530/EJE-16-0967)

25 Kołtowska-Häggström M, Kind P, Monson JP \& Jonsson B. Growth hormone (GH) replacement in hypopituitary adults with GH deficiency evaluated by a utility-weighted quality of life index: a precursor to cost-utility analysis. Clinical Endocrinology 200868 122-129. (https://doi.org/10.1111/j.1365-2265.2007.03010.x)

26 Monson JP. Long-term experience with GH replacement therapy: efficacy and safety. European Journal of Endocrinology, Supplement 2003 148 (Supplement 2) 9-14. (https://doi.org/10.1530/eje.0.148s009)

27 Jørgensen JOL \& Juul A. THERAPY OF ENDOCRINE DISEASE: Growth hormone replacement therapy in adults: 30 years of personal clinical experience. European Journal of Endocrinology 2018179 R47-R56. (https://doi.org/10.1530/EJE-18-0306)

28 Shimon I, Badiu C, Bossowski A, Doknic M, Dzivite-Krisane I, Hána V, Kollerova J, Natchev E, Pfeifer M, Szucs N et al. Adult growth hormone deficiency in CEE region: heterogeneity of the patient pathway. Growth Hormone and IGF Research 2019 46-47 44-49. (https://doi.org/10.1016/j.ghir.2019.06.001)

29 Consensus guidelines for the diagnosis and treatment of adults with growth hormone deficiency: summary statement of the Growth Hormone Research Society Workshop on adult growth hormone deficiency 1. Journal of Clinical Endocrinology and Metabolism 199883 379-381. (https://doi.org/10.1210/jcem.83.2.4611) 